\title{
Evaluation of a Commercial Enzyme-Linked Immunosorbent Assay Kit for Detection of IgM Antibody against Leptospira in Human Sera for Patients admitted in Malaysian Hospitals
}

\author{
Habib Abdul Hakim Esa*, Fairuz Amran and Nurul Atiqah Noor Halim \\ Bacteriology Unit, Infectious Disease Research Centre, Institute for Medical Research, Kuala Lumpur, Malaysia
}

"Corresponding author: Dr. Habib Abdul Hakim Esa, MBBS, Bacteriology Unit, Infectious Disease Research Centre, Institute for Medical Research, Jalan Pahang, 50588 Kuala Lumpur, Malaysia, Tel: +603-26162666; Fax: 603-26919716; E-mail: habib@imr.gov.my

Received date: February 19, 2018; Accepted date: February 20, 2018; Published date: March 5, 2018

Copyright: (C) $2018 \mathrm{Esa} \mathrm{HAH}$, et al. This is an open-access article distributed under the terms of the Creative Commons Attribution License, which permits unrestricted use, distribution, and reproduction in any medium, provided the original author and source are credited.

\begin{abstract}
Leptospirosis is an infectious zoonotic disease caused by corkscrew shaped of pathogenic Leptospira spp. Early diagnosis is important as the disease can be treated with antibiotic to prevent complications. The gold standard of leptospirosis diagnosis is microscopic agglutination test (MAT). However, the test is laborious and time consuming. This study aimed to evaluate whether a commercial ELISA (enzyme-linked immunosorbent assay) kit by VirionSerion can demonstrate antibody against leptospires for accurate and rapid screening for leptospirosis. A total of 212 serum samples were tested with Virion-Serion Classic ELISA IgM, which was earlier collected from patient with clinical manifestation suggestive of leptospirosis in Malaysia and confirmed with MAT. The results were analyzed into two categories. In the first category all samples that were positive with MAT but detected as intermediate by the ELISA were not included. In the second category, all sample that positive with MAT but detected as intermediate were included. When the intermediate results were excluded, the clinical sensitivity was $73 \%$ and clinical specificity was $94 \%$. When the intermediate results were included, the clinical sensitivity and specificity were $75 \%$ and $85 \%$ respectively. From this finding we can conclude that Virion-Serion ELISA IgM Classic kit have a reasonably appropriate performance and can be used for screening and diagnosis for leptospirosis in acute febrile illness however it should be confirmed later with the gold standard serological test which is MAT.
\end{abstract}

Keywords: Diagnostics; Leptospirosis; Enzyme-linked immunosorbent assay test

\section{Introduction}

Leptospirosis is an infectious zoonotic disease caused by corkscrew shaped bacterium of pathogenic Leptospira spp. The disease can have clinical presentations from mild influenza-like illness to severe manifestation such as meningitis, meningoencephalitis and pulmonary haemorrhage with respiratory failure [1]. The clinical presentation can overlapped with other causes of acute febrile illness making thereby clinical diagnosis difficult [1]. Delayed treatment can cause the progression of the disease from bacteremia phase to immune (delayed) phase which can be fatal and difficult to treat [2]. Early diagnosis is important as antibiotic therapy can be started early and prevent the progression to immune (delayed) phase in which antibiotic therapy is rendered useless [3]. Leptospirosis remained endemic in Malaysia and increased numbers of cases are observed from 2012-2013 with total fatality rate of $1.47 \%$ [4]. The current rapid tests for leptospirosis available in Malaysia have low diagnostic sensitivity so there is a need to have a diagnostic kit that are both specific and sensitive [5]. The gold standard test which is MAT requires maintenance of a large panel of live Leptospira stock cultures, laboratory technical expertise [6] and are only available in certain diagnostic centres such as Institute for Medical Research (IMR), Kuala Lumpur [1]. The polymerase chain reaction (PCR) for nucleic acid detection also requires high technical skills and not readily available in most pathology laboratories [1]. Isolation of leptospires from clinical samples can delay the diagnosis up to two weeks [6]. Therefore, a simple, accurate and reliable test in comparison to MAT is very much needed to help physician make an accurate clinical management.

In this study, we evaluated a commercial ELISA, Virion/Serion IgM classic test for detection of IgM antibody against Leptospira spp. for usage in rapid screening of acute leptospirosis cases in admitted in Malaysian hospitals. The test is both qualitative and quantitative. The principle of the test is based on specific interaction of antibodies (from patient's serum, plasma, blood) with coated antigen in the wells of test strips. If there is antibody present in the patient serum it will form immune complex with the antigen. A secondary antibody specific to IgM against Leptospira spp. which has been conjugated with alkaline phosphatase is added and bind to the immune complex. P-nitrophenyl phosphate substrate which is colourless is added and will be converted into coloured products p-nitrophenol. The signal intensity from the reaction is measured photo metrically at $405 \mathrm{~nm}$ wavelength.

\section{Materials and Method}

A total of 212 of randomly selected serum sample were selected with 108 serum samples tested positive and 104 serum samples tested negative for leptospirosis using MAT. The samples are retrospectives sample from patients admitted to various Malaysian hospitals in year 2014 that had acute febrile illness and suspected to have leptospirosis. Forty serum samples from patients present with acute febrile illness and positive with Dengue, Typhus, Syphilis (VDRL), Scrub Typhus or Meliodosis were also tested to check for cross-reactivity 
Citation: Esa HAH, Amran F, Halim NAN (2018) Evaluation of a Commercial Enzyme-Linked Immunosorbent Assay Kit for Detection of IgM Antibody against Leptospira in Human Sera for Patients admitted in Malaysian Hospitals. Clin Microbiol 7: 306. doi: $10.4172 / 2327-5073.1000307$

Page 2 of 4

\section{Micro agglutination test (MAT)}

The randomly selected samples were examined by MAT using a panel of 20 serotypes and strains. Six locally isolated strains and the rest is reference strains obtained from World Health Organizations (WHO) Collaborative Centre for Leptospirosis in Amsterdam which are serovars Australis, Autumnalis, Bataviae, Ballum, Canicola, Grippotyphosa, Icterohaemorrhagiae, Javanica, Pomona, Pyrogenes, Tarrasovi, Sejroe and Patoc were used. The test was carried out at National Reference Laboratory for Leptospirosis, Institute for Medical Research by using WHO standard protocols to detect total leptospiral antibody. A sample is considered positive when there is a fourfold rise in titre between acute and convalescent sera or when a single serum specimen has a titre 400 or more. A sample is negative when the MAT titre is less than 50 or there is no fourfold rise in titre between acute and convalescent sera.

\section{Enzyme-linked immunosorbent assay (ELISA)}

The Virion-Serion ELISA Classic IgM Leptospirosis claimed by the manufacturer able to detect IgM antibody against Leptospires. All of 212 samples were performed using the kit with manufacturer's instruction. All of reagents were brought to room temperature before testing. The sera were also prepared to remove rheumatoid factor that may present before running test. The procedures were simplified in figure 1.

Sample dilution: $10 \mathrm{ul}$ of sample $+1000 \mathrm{ul}$ dilution buffer

Pipette diluted samples and ready-to-use control sera

/ standard sera into microtest wells ( $10 \mathrm{ul})$

INCUBATION: $60 \mathrm{~min} . / 37 \mathrm{C}$ moist chamber

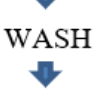

Pipette conjugate solution into wells (100ul)$$
\checkmark
$$

INCUBATION: $30 \mathrm{~min} . / 37 \mathrm{C}$

moist chamber

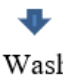

Wash

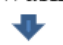

Pipette substrate solution (100 ul)

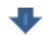

INCUBATION: $30 \mathrm{~min} . / 37 \mathrm{C}$ moist chamber

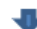

Pipette stopping solution (100ul)

7

\section{READ EXTINCTION AT $405 \mathrm{~nm}$}

Figure 1: Test procedure for Virion-Serion ELISA IgM against Leptospira.

\section{Result}

The definition of diagnostic sensitivity, specificity, positive predictive value (PPV) and negative predictive value (NPV) are shown in the Table 1.

\begin{tabular}{|l|l|}
\hline Sensitivity & $\begin{array}{l}\text { The sensitivity of the ELISA to detect a case was defined } \\
\text { as percentage of leptospirosis cases that were correctly } \\
\text { by the assay based on positive result from one or more } \\
\text { specimen. }\end{array}$ \\
\hline Specificity & $\begin{array}{l}\text { The specificity of the ELISA to detect sera that do not } \\
\text { contain antibody to Leptospira spp. when standard } \\
\text { reference test is negative. }\end{array}$ \\
\hline PPV & $\begin{array}{l}\text { The probability of the serum does contained antibodies } \\
\text { when the test is positive. }\end{array}$ \\
\hline NPV & $\begin{array}{l}\text { The probability of the serum does not contained } \\
\text { antibodies when the test is negative. }\end{array}$ \\
\hline
\end{tabular}

Table 1: Definition of sensitivity, specificity, positive predictive value and negative predictive value.

In the first category of analysis, all the intermediate result by the ELISA kit is excluded. The total number of positive cases is 101 and total number of negative cases is 99 . The case sensitivity is $73 \%$ and case specificity is $94 \%$. The positive predictive value (PPV) is $93 \%$ and negative predictive value (NGV) is $78 \%$. Results are as tabulated below in Tables 2A and 2B.

\begin{tabular}{|c|c|c|c|c|}
\hline \multirow{3}{*}{$\begin{array}{l}\text { ELISA IgM } \\
\text { (intermediate } \\
\text { excluded) }\end{array}$} & \multicolumn{3}{|c|}{ MAT } & \multirow[t]{2}{*}{ Total } \\
\hline & & Positive & Negative & \\
\hline & Positive & 74 (true positive) & 6 (false positive) & 80 \\
\hline & Negative & 27 (false negative) & 93 (true negative) & 120 \\
\hline & & 101 & 99 & 200 \\
\hline
\end{tabular}

Table 2A: Test results using ELISA against MAT as 'gold standard' (excluded intermediate).

\begin{tabular}{|c|c|c|c|c|}
\hline & \multicolumn{3}{|c|}{ MAT } & Total \\
\hline \multirow{4}{*}{$\begin{array}{l}\text { ELISA IgM } \\
\text { (intermediate } \\
\text { included) }\end{array}$} & & Positive & Negative & \\
\hline & Positive & 81 (true positive) & 11 (false positive) & 92 \\
\hline & Negative & 27 (false negative) & 93 (true negative) & 120 \\
\hline & & 108 & 104 & 212 \\
\hline
\end{tabular}

Table 2B: Test results using ELISA against MAT as 'gold standard' (included intermediate).

In the second category of analysis, all the intermediate results by ELISA kit were included. The intermediate results with positive MAT were considered as true positive and the intermediate results with negative MAT were considered as false positive. The number of positive cases is 108 and the number of negative cases is 109 . The case sensitivity increased to $75 \%$ and case specificity reduced to $85 \%$. PPV reduced to $88 \%$ and NPV remained the same at $78 \%$. Results are tabulated in Table 3 . 
Citation: Esa HAH, Amran F, Halim NAN (2018) Evaluation of a Commercial Enzyme-Linked Immunosorbent Assay Kit for Detection of IgM Antibody against Leptospira in Human Sera for Patients admitted in Malaysian Hospitals. Clin Microbiol 7: 306. doi: 10.4172/2327-5073.1000307

Page 3 of 4

\begin{tabular}{|l|l|l|}
\hline & Intermediate excluded & $\begin{array}{l}\text { Intermediate included as } \\
\text { positive }\end{array}$ \\
\hline Sensitivity & $73 \%$ & $75 \%$ \\
\hline Specificity & $94 \%$ & $85 \%$ \\
\hline $\begin{array}{l}\text { Positive Predictive } \\
\text { Value }\end{array}$ & $93 \%$ & $88 \%$ \\
\hline $\begin{array}{l}\text { Negative } \\
\text { Predictive Value }\end{array}$ & $78 \%$ & $78 \%$ \\
\hline
\end{tabular}

Table 3: Sensitivity, Specificity, Positive Predictive Value (PPV) and Negative Predictive Value (NPV) of the ELISA against MAT as gold standard.

\section{Discussion}

Leptospirosis is treatable if treatment administrated in adequate time [1,3]. Although MAT is the gold standard diagnostic tool for leptospirosis the result will take at least two days and this test is only available in specialized diagnostic centre because of certain technical expertise requirement. A reliable and faster screening test should be available to help physician to differentiate leptospirosis from other cause of acute febrile illness [5].

The results shown that the ELISA has a better level of performance as compared to previously evaluated Leptospirosis rapid test that available in Malaysia [5]. The sensitivity is minimally improved with the addition of interpretation for 'intermediate' as positive. Patients with 'intermediate' result might have low IgM antibody level due to early stage of infection or delayed seroconversion. Delayed seroconversion might be caused by early antibiotic initiation [7]. A second paired serum sample is recommended to look for rise in antibody titre as evidence for acute leptospirosis [1,8]. Although laboratory test is required for confirmation of diagnosis, treatment should not be delayed by negative result especially in cases with history that suggestive of leptospirosis [8].

The performance of the kit indicated that it can be a satisfactory screening test and a reasonably reliable confirmatory test in laboratories that do not have facilities for MAT. The ELISA is fast and simple to perform but requires specialized equipment such as photometer, therefore make it slightly difficult compared to rapid test. The ELISA test can be completed within a day as compare to MAT which will take at least two days. Although ELISA interpretation is less subjective as compare to MAT, ELISA should performed by trained person to make sure correct reading and interpretation of the result and also to minimize opera. ELISA can be recommended in secondary health care centre where sending samples to specialized diagnostic will cause delayed in laboratory diagnosis.

Cross-reactivity with other disease can occurred if the patient had co-infection or cross- reactive antibodies [9] especially in early phase of disease where IgM is known to be less specific compared to IgG class antibodies. Minimal cross reactivity is observed with Dengue, Syphilis, VDRL, and Scrub Typhus (Table 4). Confirmation test need to be carried out to confirm the diagnosis if there is any doubt.

\begin{tabular}{|l|l|l|l|}
\hline $\begin{array}{l}\text { Serum samples tested } \\
\text { positive serologically } \\
\text { to other infectious } \\
\text { disease }\end{array}$ & \multicolumn{2}{|l|}{ Virion-Serion ELISA IgM } & $\begin{array}{l}\text { Percent cross } \\
\text { reactivity between } \\
\text { ELISA and MAT }\end{array}$ \\
\cline { 2 - 3 } & Positive & Negative & \\
\hline
\end{tabular}

\begin{tabular}{|l|l|l|l|}
\hline Dengue (10) & 1 & 9 & $10 \%$ \\
\hline Typhus (5) & 0 & 5 & $0 \%$ \\
\hline Syphilis (VDRL) (5) & 1 & 4 & $20 \%$ \\
\hline Scrub Typhus (10) & 2 & 8 & $20 \%$ \\
\hline Meliodosis (10) & 0 & 5 & $0 \%$ \\
\hline
\end{tabular}

Table 4: Cross reactivities Virion Serion ELISA IgM against Leptospira with other cause of disease.

In summary, Virion-Serion ELISA IgM Classic test kit has a reasonability appropriate diagnostic value. The test is much simpler and faster to perform when compare to MAT. It also has better performance when compare to previously evaluate rapid test in Malaysia. However more sensitive test should be developed to help physician for diagnosing acute leptospirosis in especially in secondary hospital. The diagnostic kit might be useful in situation where diagnostic centre that provide MAT were far away from health centre and prompt diagnosis is really required for patient management.

\section{Conclusion}

The Virion-Serion ELISA IgM Classic kit is a good alternative to MAT when prompt diagnosis is required. The test kit has reasonably good sensitivity and specificity which make it an appropriate screening tool and a fairly good confirmatory tool for leptospirosis in health center that do not have technical specialties for MAT.

\section{Acknowledgement}

We thank the Director General of Ministry of Health Malaysia for permission to publish this manuscript.

\section{Ethical Statement}

No experimental work with humans or animals has been done for this study.

\section{Disclosure}

The authors of this study have no work in relation with the company Institute Virion|Serion $\mathrm{GmbH}$, German or its products. All authors declare that there is no conflict of interest in this study to disclose.

\section{Author's Contribution}

Research study \& design: Fairuz Amran. Data acquisition: Fairuz Amran. Running of MAT assay: Nurul Atiqah Noor Halim. Evaluation of rapid kit: Nurul Atiqah Noor Halim. Data analysis and interpretation: Habib Abdul Hakim Esa. Drafting and writing of the manuscript: Habib Abdul Hakim Esa. Critical revision of the manuscript: Fairuz Amran. Approval of final manuscript: all authors.

\section{References}

1. Verasahib KB, Ngadiman SB, Rahim DA, Satiamurti A, Ariffin RB, et al. (2011) Guidelines for the Diagnosis, Management, Prevention and Control of Leptospirosis in Malaysia. Minist Heal Malaysia 41. 
Citation: Esa HAH, Amran F, Halim NAN (2018) Evaluation of a Commercial Enzyme-Linked Immunosorbent Assay Kit for Detection of IgM Antibody against Leptospira in Human Sera for Patients admitted in Malaysian Hospitals. Clin Microbiol 7: 306. doi: $10.4172 / 2327-5073.1000307$

Page 4 of 4

2. Bharti AR, Nally JE, Ricaldi JN, Matthias MA, Diaz MM, et al. (2003) Leptospirosis: a zoonotic disease of global importance. Lancet Infect Dis 3: 757-771.

3. Pappas G, Cascio A (2006) Optimal treatment of leptospirosis: queries and projections. Int J Antimicrob Agents 28: 491-496.

4. Tan WL, Soelar SA, Mohd Suan MA, Hussin N, Cheah WK, et al. (2016) Leptospirosis Incident and Mortality in Malaysia. Southeast Asian J Trop Med Public Health 47: 434-440.

5. Chang CH, Riazi M, Yunus MH, Osman S, Noordin R (2014) Limited diagnostic value of two commercial rapid tests for acute leptospirosis detection in Malaysia. Diagn Microbiol Infect Dis 80: 278-281.
6. Musso D, La Scola B (2013) Laboratory diagnosis of leptospirosis: a challenge. J Microbiol Immunol Infect 46: 245-252.

7. Katz AR (2012) Quantitative polymerase chain reaction: filling the gap for early leptospirosis diagnosis. Clin Infect Dis 54: 1256-1258.

8. Goris MGA, Leeflang MMG, Loden M, Wagenaar JFP, Klatser PR (2013) Prospective evaluation of three rapid diagnostic tests for diagnosis of human leptospirosis. PLoS Negl Trop Dis 7: e2290.

9. Levett PN (2001) Leptospirosis. Clin Microbiol Rev 14: 296-326. 